\title{
LA CASA DEL CABILDO: INMUEBLE Y SOLAR EN EL PAISAJE URBANO DEL BARROCO COMPOSTELANO ${ }^{1}$
}

Contacto autor: miguel.tain@usc.es

RESUMEN:

La reciente rehabilitación de la Casa del Cabildo de Santiago de Compostela por el Consorcio de Santiago, abierta al público a comienzos de 2012, ha permitido estudiar nuevos aspectos del solar y el edificio construido, el máximo exponente de las fachadas telón del barroco compostelano. A los resultados más novedosos se dedica el presente artículo, ilustrado con las propuestas del autor sobre las plantas y alzados de las casas anteriores al monumento y con un dibujo en el que se señala qué muros son nuevos y cuáles reaprovechados.

Palabras clave: Santiago de Compostela, Casa del Cabildo, barroco, fachada telón.

\section{ABSTRACT:}

The Consortium of Santiago's recent restoration of the chapter house, which opened to the public at the start of 2012, provided an opportunity to study new aspects of the site and the building, which boasts the finest Baroque screen facade in Santiago de Compostela. The most important findings of the study can be found in this paper, a text illustrated with the author's proposals with regard to the floor plans and elevations of the houses that occupied the site prior to the building, and with a drawing indicating which walls are new and which have been reused.

Keywords: Santiago de Compostela, chapter house, Baroque, screen facade.

Todo es caprichoso: se emplean desusados motivos de decoración, se rompe el entablamento, se decapitan las columnas, se da mayores proporciones a las cornisas, se prescinde de toda razón y regla

Murguía, M., El Arte en Santiago durante el siglo XVIII, Madrid, 1884.

En el ecuador del siglo XVIII el cabildo de la Catedral de Santiago cierra su programa de reformas en la Plaza de las Platerías con la construcción de la hoy conocida como Casa del Cabildo entre 1755 y 1759 , el actual número 5 de la plaza, una arquitectura de su tiempo, que busca potenciar la "dignidad" y grandeza de la ciudad". La Casa se concibe a modo de una gigantesca bambalina barroca de piedra, un nuevo decorado teatral urbano, que tiene como función monumentalizar el frente sur de la plaza y ocultar el caserío posterior a la vista de los viandantes, especialmente fieles y peregrinos que saliesen de la catedral por su puerta meridional ${ }^{3}$ (Figs. 1-4). Tal carácter decorativo, así como su destino a vivienda de artesanos de la ciudad, y 


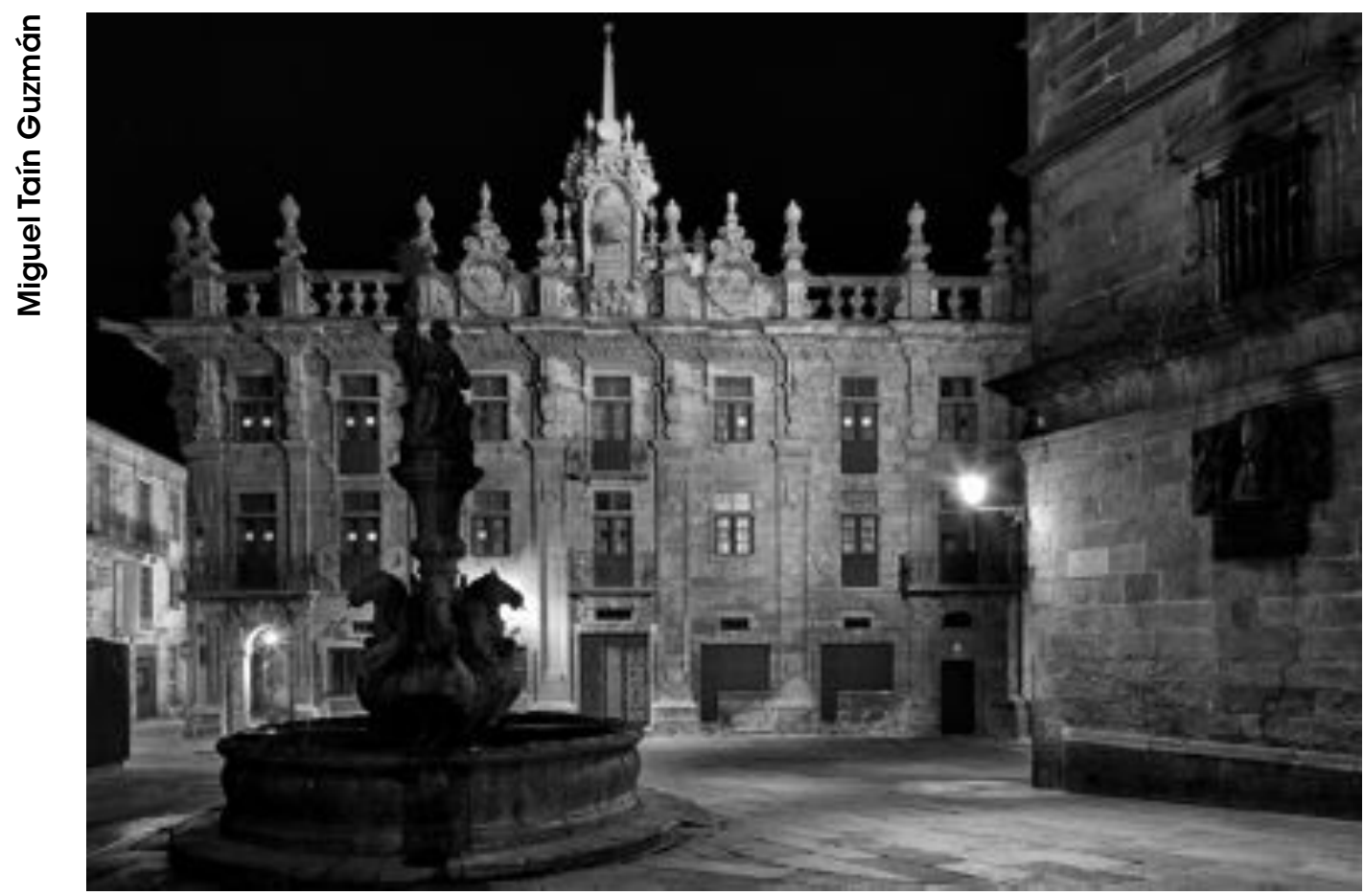

Fig. 1. Fachada de la Casa del Cabildo tras su rehabilitación por el Consorcio de Santiago y el Ministerio de Fomento, con proyecto y dirección de los arquitectos A. Martín Prieto, A. Panero Pardo y L. Pérez Castro. Foto Fuco Reyes.

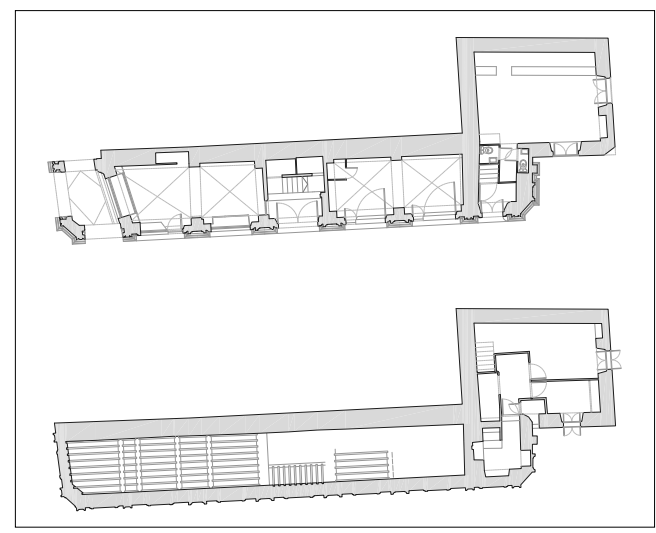

Fig. 2. Planta del bajo de la Casa del Cabildo y de la Casa de la Raíña y planta del entresuelo de la Casa de la Raíña (distribución interior anterior a la rehabilitación de 2011). Oficina Técnica-Taller de Proyectos del Consorcio de Santiago.

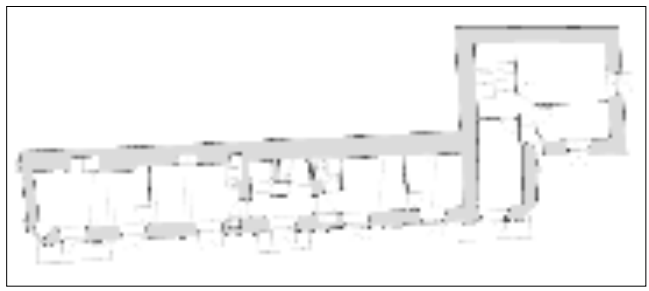

Fig. 3. Casa del Cabildo: planta del primero (distribución interior anterior a la rehabilitación de 2011). Oficina Técnica-Taller de Proyectos del Consorcio de Santiago.

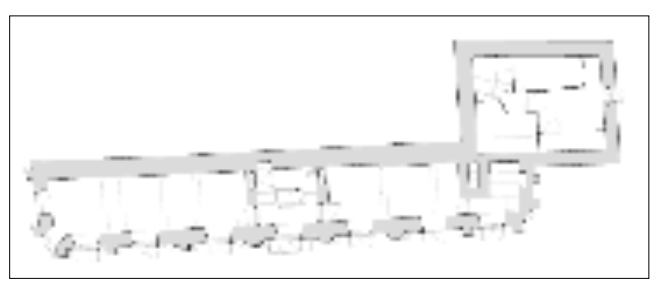

Fig. 4. Casa del Cabildo: planta del segundo (distribución interior anterior a la rehabilitación de 2011). Oficina Técnica-Taller de Proyectos del Consorcio de Santiago. 
no a residencia de un canónigo pese a ser una obra capitular, explican sus peculiares medidas y escasa profundidad: 31,48 metros en Platerías, 6,07 metros en la Rúa do Vilar y 4,44 metros en la Rúa de Fonseca. Su origen cabe relacionarlo con los decorados urbanos civiles que en el siglo XVII y la primera mitad del XVIII se llevaron a cabo en diversos enclaves urbanos con similar finalidad, particularmente en Roma, Madrid o el propio Santiago, emulando la tradición secular de renovación de las fachadas de la arquitectura religiosa delante de fábricas más antiguas ${ }^{4}$. Además, la costumbre de ocultar con arquitecturas fingidas viejas edificaciones durante las fiestas también alentará este tipo iniciativas ${ }^{5}$. En la primera ciudad, de donde acababa de llegar Diego Juan de Ulloa, el promotor de nuestro edificio, tras una no corta residencia como luego veremos, hay una larga tradición de este tipo de intervenciones desde que en 1538 Miguel Ángel sobrepuso sendas nuevas fachadas al Palacio del Senado y al Palacio de los Conservadores en la Plaza del Campidoglio, escondiendo los edificios medievales posteriores, con el fin de unificar y monumentalizar dicho espacio urbano, hasta entonces poco valorado, finalidad similar a la empresa gallega ${ }^{6}$. El éxito de la experiencia fomentó intervenciones similares en el barroco siendo muchos los palacios romanos que construyen fachadas telón para ocultar sus viejas residencias y torres nobiliarias, constituyendo un magnífico ejemplo de ello el Palacio Cenci-Bolognetti $(1737)^{7}$. También responde a la misma intención el frente palacial de la Fontana de Trevi, decorando un lateral del Palacio Poli (1735), y urbanizando una encrucijada estratégica; o, fuera de Roma, como ya señaló en su día María del Folgar de la Calle, el Palacio Madama de Turín (1721), que oculta el castillo medieval de los Saboya ${ }^{\text {. }}$ Muy interesante por sus semejanzas con el caso compostelano son las fachadas que cierran la Plaza de San Ignacio (ca.1728), ya señaladas por Rosende Valdés 9 , o los frentes palaciales de Quattri Canti de Palermo (1608-1620), en la intersección central de la ciudad, pues en ambos ejemplos se trata de "biombos" para dignificar un espacio urbano ${ }^{10}$, buscando generar un illusonismo ottico con unas buenas arquitecturas mientras el público que las observa transita por el recinto y no ve lo que hay detrás ${ }^{11}$.
En España las intervenciones de este tipo más sobresalientes son las plazas mayores, como la de Madrid (1619) ${ }^{12}$ o Salamanca (1729-1756) ${ }^{13}$, auténticas pantallas que uniformizan zonas de caserío caótico, que quedan comprimidas tras ellas, y, acaso también, el frente construido por el arquitecto Juan Gómez de Mora en el Real Alcázar para ocultar la alcazaba medieval y sus añadidos renacentistas, así como dignificar la Plaza Real (1612-1630) ${ }^{14}$. Por fin, en Compostela, aparte de ejemplos tan paradigmáticos en la arquitectura religiosa española como las diferentes fachadas catedralicias, fenómeno que ha llevado a Virginia Tovar a hablar de una "catedral sobrepuesta"15, en la arquitectura civil, también tenemos algunos precedentes, aunque no de la entidad de los ya expuestos, como la fachada del Palacio Arzobispal hacia la Plaza del Obradoiro (1611), ocultando la fábrica medieval ${ }^{16}$, o la fachada de la Casa de la Parra hacia la Plaza de la Quintana (ca.1676), que esconde el caserío de la Azabachería ${ }^{17}$.

El monumento compostelano constituye, pues, una obra maestra de la retórica arquitectónica y ornamental del setecientos, ensalzado en todas las historiografías de la arquitectura española, como las ya clásicas de Otto Schubert ${ }^{18}$, George Kubler ${ }^{19}$ o Valdivieso González ${ }^{20}$. Se trata de una arquitectura visual calculada para ser contemplada desde diferentes puntos de visión tanto desde los dos niveles de la Plaza de las Platerías, como desde el desembarco de las calles aledañas, buscando efectos diversos según la observación del espectador sea desde cerca o desde lejos ${ }^{21}$. La extraña factura a cordel del edificio, explicable por la intención de facilitar el tráfico de carros y monturas, como también la presencia de los chaflanes, se rompe en su coronamiento, donde la arquitectura adquiere densidades y movimientos, hacia atrás y hacia adelante, jugando con el vacío y el macizo, la luz y las sombras, que manifiestan las posibilidades y ductibilidad de la piedra.

Cuenta con un repertorio de motivos decorativos muy imaginativos, sino extravagantes y ostentosos, de inspiración local (motivos jacobeos), francesa (rocallas), italiana (órdenes arquitectónicos, bustos de la balaustrada y obelisco) y alemana-holandesa (placas geométricas), 
destinado a estimular las superficies del edificio y despertar la admiración de los viandantes. Tal uso de la fantasía decorativa en los elementos esculpidos del frente compostelano no es un caso aislado, constituyendo, en realidad, la gran novedad de los exteriores palaciales españoles de este siglo con otros ejemplos tan representativos como el Palacio del Marqués de Dos Aguas en Valencia, el Palacio del Marqués de Montana en Jerez de la Frontera, el Palacio de los Condes de Valverde en Écija, el Palacio de los Marqueses de Peñaflor también en Écija, el Palacio de Goyeneche y el Palacio del Marqués de Miraflores en Madrid o la misma Casa del Deán en Compostela, entre otros ${ }^{22}$. A sorprender también contribuía la policromía del edificio: la tonalidad parda del granito, el blanco del albayalde en los enmarques de la planta baja, el tradicional verde de las carpinterías ${ }^{23}$ y el dorado refulgente de las bolas de las barandas de los balcones y, es de suponer, de la estrella del remate. Esta última, dispuesta sobre el obelisco de la peineta, sede del escudo capitular, es la causa de que al inmueble se le conociera popularmente como la Casa da Estrela.

La construcción del edificio fue patrocinada y financiada por el Depósito de Música de la Catedral24, entonces administrado por el canónigo maestrescuela Diego Juan de Ulloa ${ }^{25}$, prebendado procedente de Roma instalado en la ciudad en 1733, que va a invertir 180.612 reales y 21 maravedíes en la construcción ${ }^{26}$. El proyecto y la dirección de los trabajos corresponden a Clemente Fernández Sarela, entonces Aparejador de Obras catedralicio ${ }^{27}$, quien firma orgulloso su proeza arquitectónica, con el título de arquitecto, en el dintel del vano central de la última planta del edificio:

PRO COMMODITATE, AC ORNATO URBIS, IVSSU ILLMI. CAPITVLI, SVMPTIBVS, DEPOSSITI, EXTRVI, CURAVIT SVVS ADMINISTRATOR: AN. DOMN., 1758. ARCHITECTO SARELA.

En 1999, con motivo de los intentos de compra del inmueble por la Dirección Xeral de Turismo de la Xunta de Galicia para destinarlo infructuosamente a Oficina de Turismo de la Ciudad, nos fue encargado un primer estudio histórico del mismo a través de un convenio de investigación firmado entre dicha institución y la Universidad de Santiago (referencia 1999/ Cl318). La información allí recogida, debidamente ampliada en archivos y bibliotecas gallegos, nacionales e internacionales, dio lugar, tiempo después, a la publicación de una monografía sobre el monumento, patrocinada por el Consorcio y la editorial Electa, con el título La Casa del Cabildo de Santiago de Compostela (1754-1759): Pro Commoditate ac ornato urbis, Santiago, 200028, análisis que pretendo ahora enriquecer con nuevos datos a raíz de mis últimas investigaciones.

Expropiado el edificio años después y con motivo de su rehabilitación por el Consorcio a lo largo del año 2011 para formar parte del futuro Museo Nacional de las Peregrinaciones y de Santiago, cuya sede principal será el antiguo edificio del Banco de España, dicho Consorcio requirió nuestra asesoría y un segundo informe, que complementase el anterior y ayudase a tomar decisiones en su recuperación. Además, se nos autorizó acceder por primera vez al número 6 de Platerías, lo que no se pudo hacer en 1999, lo que ha permitido analizar con rigor el interior de ese inmueble y su vinculación con el monumento. A los resultados más novedosos de nuestro trabajo, con nuevos datos sobre el solar, el palacio y sus habitantes, se dedica el presente artículo, texto ilustrado con mis propuestas sobre las plantas y alzados de las casas anteriores al edificio barroco y con un dibujo en el que se señala qué muros son nuevos y se deben a Sarela y cuáles fueron reaprovechados.

\section{LAS TRES CASAS DE PLATERÍAS}

En el momento previo a la construcción del palacio barroco el solar se hallaba ocupado por tres casas, la primera habitada por el mercader Manuel Martínez de Mestas, propiedad del Real Priorato del Sar, la segunda habitada por la familia Otero, propiedad de la Universidad ${ }^{29}$, y la tercera propiedad de la Fábrica de la Catedral ${ }^{30}$ (Figs. 5-8). Un plano de la ciudad de antes de 1754 permite conocer grosso modo las características y forma del solar ocupado por las tres casas, observándose cómo las tres se encontraban muy próximas a la Catedral, dificultando el 


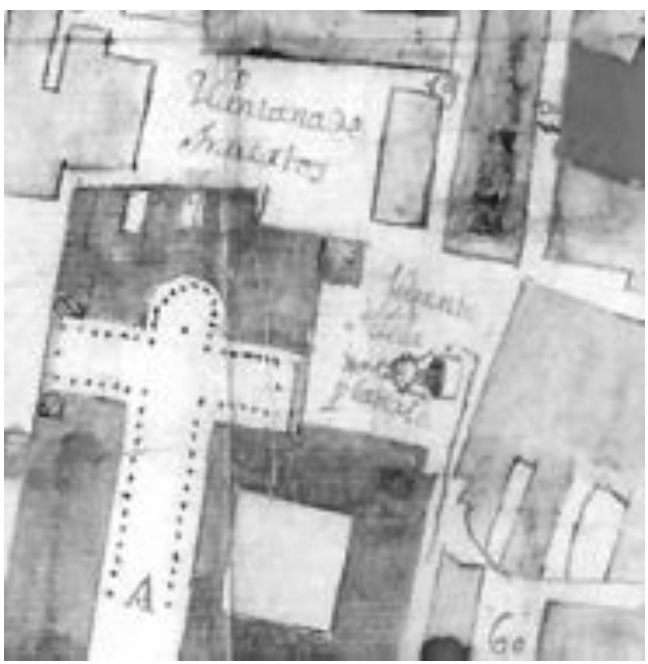

Fig. 5. Detalle de un mapa de la ciudad de Santiago, anterior a 1754, con las casas derribadas para la construcción de la Casa del Cabildo (Instituto de Estudios Gallegos Padre Sarmiento).

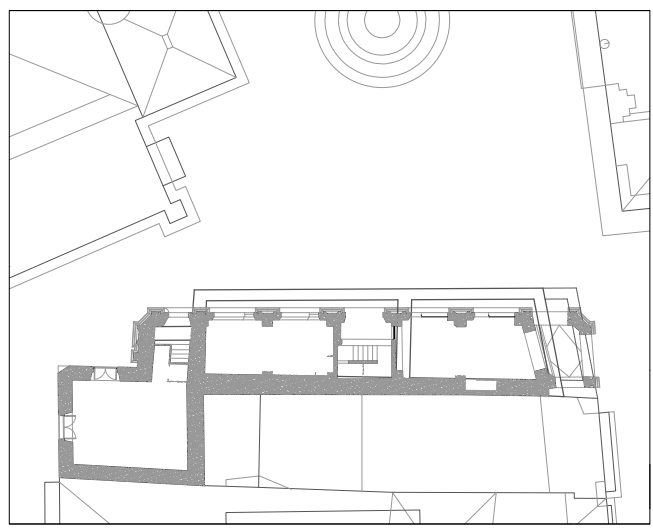

Fig. 6. Reconstrucción hipotética del solar ocupado por las tres casas anteriores a la Casa del Cabildo (sobre la planta del nuevo inmuble). Dibujo de Jorge Vázquez Couto; Oficina Técnica-Taller de Proyectos del Consorcio de Santiago. Asesoría histórica Miguel Taín.

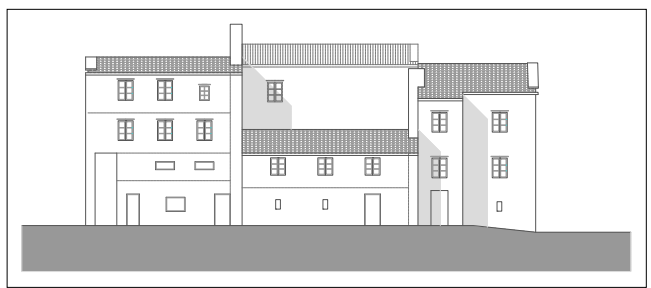

Fig. 7. Reconstrucción hipotética del alzado de las tres casas anteriores a la Casa del Cabildo. Dibujo de Jorge Vázquez Couto; Oficina Técnica-Taller de Proyectos del Consorcio de Santiago. Asesoría histórica Miguel Taín.

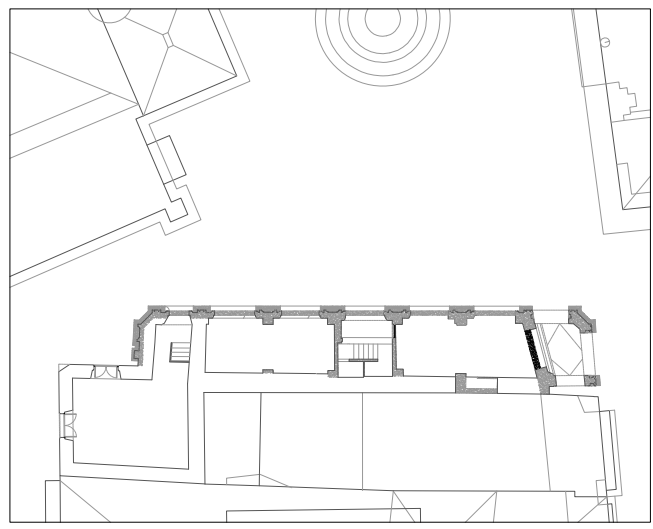

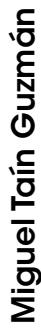

Fig. 8. Planta de la Casa del Cabildo: en negro los muros debidos al arquitecto Clemente Fernández Sarela y en blanco los muros preexistentes pertenecientes a las anteriores casas respetadas en su intervención. Dibujo de Jorge Vázquez Couto; Oficina Técnica-Taller de Proyectos del Consorcio de Santiago. Asesoría histórica Miguel Taín.

tráfico $^{31}$ (Fig. 5). Un documento de julio de dicho año, firmado por José de Avilés, intendente general de los ejércitos del rey, ofrece abundantes detalles sobre el problema:

...considerando mi partte la esttrechés y aprietto con que se halla la salida de la Rúa del Villar, una de las principales de dicha ciudad, tanto para enttrar en la Plattería, donde mira una de las fachadas de dicha Santta Yglesia, como para bolver a la nevería de ella y de alli a la Plazuela del Hospittal Real, a cuio sitio hes preciso conducir conttinuamentte ynfinidad de matteriales de madera, piedra y ottros para la obra de dicha Santta Yglesia, la acttual de los colegios de Fonseca y San Gerónimo, y todo lo demás necesario para dicho Real Hospital... las incomodidades que oi experimenta el público de no poder allí dar cónmodamente buelta los carros cargados de madera y ottros que están pattenttes a qualquiera ${ }^{32}$.

Así se explica el contenido de la primera noticia documental sobre las intenciones capitulares para la parcela, del 25 de junio, donde el cabildo decide

ser mui comveniente el que se adquieran las [dos] casas que hazen esquina a la Cruz 
del Villar ${ }^{33}$ y siguen a otra que es de la Fábrica destta Sancta Yglesia,... para el desaogo y hermosura

de la Plaza de las Platerías, de la Catedral y de la ciudad, encargando a Ulloa su adquisición, acción que gestiona con gran éxito en las semanas siguientes ${ }^{34}$. En efecto, las dos primeras casas van a ser compradas por el Depósito de Música y luego completamente demolidas. En cambio, la propiedad de la tercera va a continuar en manos de la Fábrica que sólo autorizará derruir una parte, la que da hacia la plaza, manteniéndose el resto, la actual casa número 1 de la calle de la Raíña. Un protocolo de 1768 así lo indica:

y de dichas dos casas y otra de la misma Fábrica a echo y reedificado una toda de sillería a grandes espensas, que es la que haze frente a la Fuente de la Platería ${ }^{35}$.

Por otro lado, la presencia de la inscripción RL UNIVD (REAL UNIVERSIDAD) en la pilastra izquierda que flanquea el acceso central del edificio indica que la institución académica mantuvo algún tipo de derecho sobre la propiedad.

Un atento estudio de estas tres casas, con sus diferentes alzados, distribución interna y derechos de uso (en soportales, puertas y chimeneas), explican la configuración final del inmueble actual.

\section{La Casa de Manuel Martínez de Mestas}

La primera casa, empezando por la izquierda, contaba con dos fachadas, una a la Plaza de las Platerías por el norte y otra a la Rúa do Vilar por el este, así como con dos paredes medianeras, una con la Casa de la familia Otero al oeste, de la que hablaremos a continuación, y otra al sur, según la documentación con la Casa de Juan Suárez Flores, entonces habitada por el mercader Juan Hernández ${ }^{36}$ (Figs. 5-8).

Las características y medidas del inmueble las conocemos gracias a un informe de Fernández Sarela y del maestro carpintero José Crespo, fechado el 9 de septiembre de 1754, pocas semanas antes de su demolición ${ }^{37}$. Según éste, la casa constaba de un bajo, un entresuelo y dos plantas, los cuales, desde la calle hasta el tejado, alcanzaban la altura de 10,7 metros ${ }^{38}$. El frente de Platerías, hasta el bajo del soportal, medía alrededor de 7,31 metros (8 varas y 3 cuartas), y hasta el Vilar alrededor de 9 metros (el soportal medía 8 cuartas menos 4 dedos). En cambio, la fachada del Vilar contaba con alrededor de 4,8 metros de ancho (6 varas menos 9 dedos).

Todo el frente del Vilar era asoportalado, terminando la hilera de soportales de esa vertiente de la calle y permitiendo la desembocadura del gentío en Platerías. Contaba con una columna como elemento de sostén y albergaba una tienda adintelada con su puerta y dos mostradores (tableros) para trabajar y ofrecer productos a la venta. Encima, las paredes eran ligeras, de ladrillo y madera de castaño, abriéndose en el entresuelo cuatro ventanas, en la primera planta tres, sin maineles, y en el segundo tres más pequeñas.

En el frente de Platerías, en el bajo, se abría el arco adintelado del soportal y se disponían una puerta de dos tiendas, una ventana y la puerta de acceso al edificio. En el entresuelo, dos ventanas más cortas. En la primera planta, contando el voladizo sobre el soportal, otras tres; y en la segunda planta, dos y una tercera más corta próxima al muro medianero.

En cuanto a la distribución interior, la referida entrada de Platerías se hallaba en el medianil con la Casa de los Otero, de la que hablaremos a continuación, accediéndose a unas escaleras que comunicaban ambas viviendas con la calle. Sus doce peldaños desembocaban en el entresuelo con su alcoba y una chimenea francesa, con bocal de cantería, dispuesta en el medianil con los Otero. En cambio, el primer piso, volando sobre el soportal, presentaba una sala con dos alcobas hacia el Vilar, un "retiro" hacia Platerías, un vertedero en un rincón y la caja de las escaleras que comunicaban interiormente las diferentes plantas de este inmueble. Por fin, el último piso únicamente contaba con las paredes que contenían la caja del desembarco de las escaleras.

\section{La Casa de los Otero}

A cordel con la anterior se hallaba la casa de la familia Otero, la cual conocemos gracias a dos informes previos a su demolición (Figs. 5-8). Se 
trata del informe escrito por Fernando de Casas, maestro de obras Catedralicio, el 28 de junio de $1731^{39}$ y del escrito por Fernández Sarela y José Crespo el 9 de septiembre de $1754^{40}$.

Siguiendo a estos, la casa era más baja que la anterior, constando de un bajo y una única planta, alcanzando la altura de alrededor de 4,6 metros desde la calle hasta el tejado (5,5 varas y 2 dedos). Sus límites eran la Plaza de las Platerías al norte y tres paredes medianeras, una a la izquierda con la citada casa de Martínez de Mestas, otra a la derecha con la casa de la Fábrica, pared que todavía existe, aunque recortada, de unos 68 centímetros de grosor ${ }^{41}$, y una tercera, trasera, con la Casa de Juan Suárez Flores ${ }^{42}$, que también perdura. Su fachada, siempre hacia Platerías, medía alrededor de 10,5 metros (12 varas y 2,5 cuartas) y contaba con una profundidad de alrededor de 4,4 metros (en la medianera este 5 varas y 1,5 cuartas y en la oeste 5 varas, 1 cuarta y dos dedos) ${ }^{43}$. No se hallaba en línea con la casa de la Fábrica, sino adelantada alrededor de 2 metros (10 cuartas menos 3 dedos), constituyendo una extraña disonancia en el cierre de la plaza.

En el bajo se encontraba la entrada compartida al inmueble, por la que también se accedía a la casa de Martínez de Mestas, como ya hemos visto. En el pequeño zaguán allí dispuesto se abrían dos puertas en el medianil, una para la bodega y otra de acceso al piso terreno de la vivienda, y se disponían las escaleras, también compartidas con la casa vecina, que ascendían a la planta superior. La bodega se iluminaba con dos tragaluces dispuestos en la fachada de Platerías, frente en el que también se abría la puerta de acceso a la cuadra y a unas escalerillas de servicio que llevaban a la cocina.

La primera planta, el área residencial, contaba con una antesala adonde desembocaban las escaleras principales y tres estancias, una calificada como "una especie de alcoba", otra como zona de paso y la tercera como cuarto principal, cada una de ellas con una ventana hacia Platerías. También se disponía en esta planta la cocina con pavimento baldosado, su piedra de cantería en el hogar sin campana, un vertedero también de piedra y una bufarda. Un fayado aislaba la casa de la cubierta, de una sola agua, apoyada en la medianera con la casa de los Flores, a la que podrían pertenecer los huecos hallados tapiados en la misma que servirían para apoyar los pares de la armadura del tejado.

Dada la escasa altura de este inmueble, y por encima de la hilera de huecos antes mencionados, la casa colindante de los Flores abría una ventana hacia Platerías, hoy tapiada ${ }^{44}$.

\section{La Casa de la Fábrica}

La Casa de la Fábrica constituye la única de las tres que sobrevive hasta nuestros días, habiendo sólo perdido la fachada de Platerías, serrada al construirse la Casa del Cabildo (Figs. 1-9). El citado plano de la ciudad de antes de 1754 recoge grosso modo su peculiar planta antes de la intervención barroca (Fig. 5). Comparándola con la actual concluimos que conserva inalterada su forma en L, al sobresalir un brazo corto hacia la plaza, que es el que va a ver suprimido su pared norte de cierre al ser sustituida por el séptimo tramo del nuevo inmueble barroco ${ }^{45}$.

Tal planta provoca que presente cuatro frentes y varias medianías. El citado frente hacia Platerías del esconce, que, como hemos dicho, desaparece, sustituido por la obra de Fernández Sarela, aunque en él se seguirá disponiendo el acceso, el portal actual de la plaza con el número 6. Un segundo frente, del esconce, hacia el oeste, hacia la Rúa Fonseca, donde la pared original de la casa aparece envuelta por el muro barroco, obligando a tapiar las ventanas originales. Un tercero, retranqueado, también hacia la Rúa Fonseca y de orientación norte, que conserva el muro original, aunque los vanos pueden haber sido modificados. Y un cuarto, hacia el oeste, en la Rúa da Raíña, que también se mantiene, aunque también con cambios en los vanos: la puerta abierta hacia la Raíña, ostentando el número 1 de la citada calle, es probable que se trate de un antiguo acceso a las cuadras de la casa, debiéndose su presente amplitud a una intervención moderna.

Igualmente cuenta con dos paredes medianeras, respetadas por la intervención del siglo XVIII. La de la izquierda, de orientación este, colinda, primero, antes de la empresa barroca, con la Casa de los Otero, y hoy con la vivienda derecha de la Casa del Cabildo, y, luego, con el 
caserío de la Rúa do Vilar. La otra medianera es la trasera de la casa, al sur, hoy compartida con el caserío de la Raíña. Todos los muros son de mampostería, utilizándose sillería solamente en los vanos. Su configuración y alturas antes de la intervención del 2011, un bajo y tres plantas, es grosso modo la original.

De su distribución interior primitiva cabe señalar lo siguiente ${ }^{46}$ : como ya se ha dicho, el bajo, con entrada por la Raíña es probable que sirviera de cuadra. En la primera planta, se ha localizado el tiro de una lareira y restos de la misma, así como un vertedero en una antigua ventana, todo ello perteneciente a una cocina. En la segunda planta se hallan también restos del tiro de otra lareira de otra cocina, en este caso suprimida luego cuando fue trasladada al fayado reformado para la ocasión ${ }^{47}$ (Fig.10). El nivel del suelo de este piso es muy superior al de la primera planta de la Casa del Cabildo, lo que obliga a descender varios escalones si se quiere

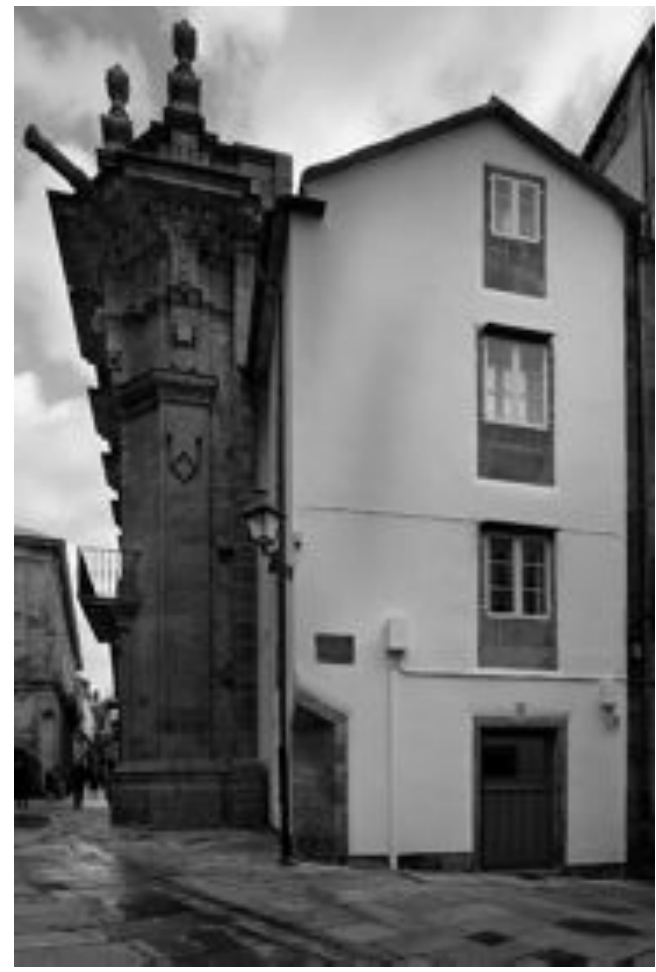

Fig. 9. Casa de la Raíña; fachada hacia la Rúa da Raíña. Foto Fuco Reyes. acceder al balcón que le corresponde, dispuesto en la fachada barroca. Como en la primera planta, el vano de la casa original, al quedar envuelto por el lienzo barroco, se utilizó como vertedero. Ambos, junto con el de la nueva cocina de la Casa del Cabildo de la segunda planta, de la que luego se tratará, vertían las inmundicias por un gigantesco arcaduz de piedra exterior situado en la pared oeste del monumento y acoplado a éste posteriormente (Fig. 9). La existencia de dos cocinas se explica por la división del inmueble en dos viviendas, una por planta, hecho del que todavía guardan recuerdo los vecinos de la zona.

Los tiros de las dos chimeneas del primer y segundo piso se han construido paralelos, atravesando el cañón la segunda planta de la Casa del Cabildo, empequeñeciendo su superficie útil. Todavía hoy es posible discernir como Fernández Sarela recreció su altura para sobresalir sobre la cubierta y evacuar los humos con comodidad (Fig.11). Es más, dada la diferente tonalidad de

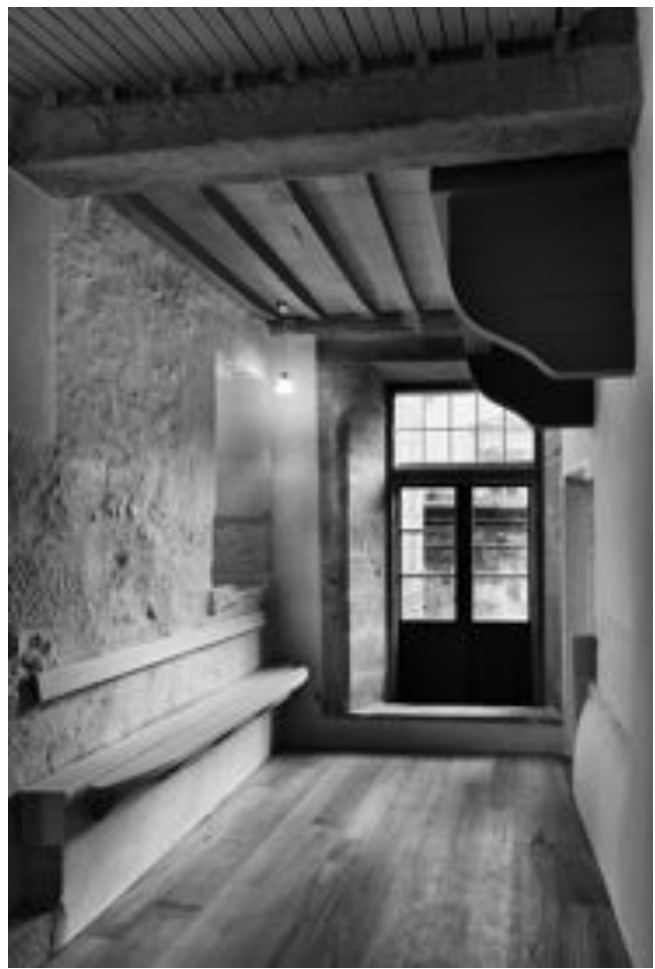

Fig. 10. Casa de la Raíña: esconce hacia Platerías con la antigua cocina. Foto Fuco Reyes. 


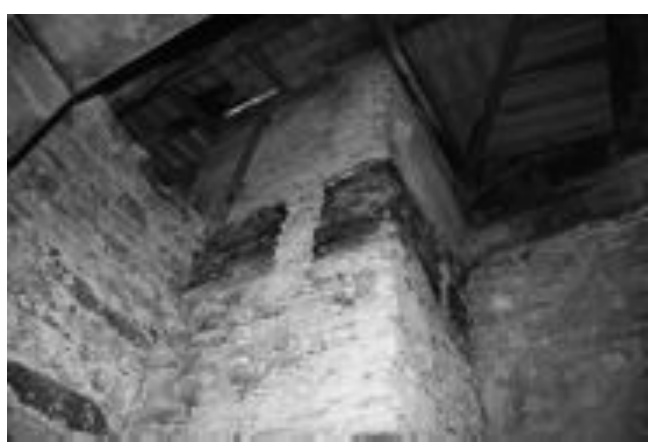

Fig. 11. Cañón de los dos tiros de las chimeneas de la Casa de la Raína que atraviesa la segunda planta de la Casa del Cabildo; obsérvense los restos de los respiraderos del cañón original y el recrecido a raíz de la obra barroca.

la piedra entre el cañón antiguo y lo añadido se pueden todavía diferenciar los antiguos partehumos de la primitiva caperuza.

\section{EL SOLAR VERSUS LA CASA DEL CA- BILDO}

La configuración de las dos casas demolidas, junto a la superviviente de la Fábrica, explica muchas de las características del diseño del arquitecto Clemente Fernández Sarela para la Casa del Cabildo. En primer lugar, la escasa profundidad de la planta del inmueble se debe al deseo capitular por ampliar la superficie de la Plaza de las Platerías, lo que llevó a reducir la superficie construida. En efecto, en el plano de la ciudad de antes de 1754, donde figura el solar de las tres casas, observamos como sobre todo las dos primeras ocupan mucho más espacio que el actual inmueble, que se hizo retroceder y dispuso en línea con la Rúa de Xelmírez (Figs. 5-6). La premisa capitular de 1754 de que la intervención sirviese principalmente "para el desaogo y hermosura" de las Platerías explica tanto esta construcción a cordel del nuevo edificio, con un desarrollo muy plano de molduras, marcos y soportes en el bajo y primeras plantas, para no interrumpir el tráfico de personas, carros y monturas $^{48}$, como la reducción de la parcela edificable a favor de la plaza: un documento afirma que, para uso público, se había "dejado la mitad del terreno de dichas casas para ensanchar la calle pública" ${ }^{49}$. Así se entiende la poca profundidad interna del nuevo inmueble, alrededor de 2,83 metros en el extremo este ${ }^{50}$ y 2,63 metros en el extremo oeste ${ }^{51}$, así como sus 414,39 $\mathrm{m}^{2}$ de superficie construida y 206, $67 \mathrm{~m}^{2}$ de superficie útil.

La compartimentación de las casas de Martínez de Mestas y de la familia Otero, que se tienen que demoler, compartiendo, como hemos visto, la entrada y unas escaleras de acceso, va a determinar que la Casa del Cabildo presente la misma distribución interna (contrastar fig. 7 con la 3 y la 4). En efecto, en su interior se habilitan dos viviendas, de dos plantas, comunicadas por las escaleras centrales, entre dos paredes maestras transversales de cantería, con entrada por el portalón principal del edificio (Fig. 12). Su morfología se acerca al concepto de "casa mínima" explicado por Blasco Esquivias para la vivienda española de época52. Entre las dos ocupan los seis primeros tramos de la primera planta de la fachada (en torno a $60 \mathrm{~m}^{2}$ ) y los siete de la segunda $\left(64,28 \mathrm{~m}^{2}\right)$. En la primera planta de la vivienda izquierda, en la zona próxima al acceso, se conserva todavía hoy la lareira de la cocina, con una alacena y vertedero, presentando la zona el característico pavimento de losas de cantería para evitar incendios ${ }^{53}$, siendo probable que en origen la estancia estuviera cerrada con algún tipo de tabique (Fig. 13). En la misma planta del apartamento de la derecha, a raíz de la supresión de los enfoscados y suelos con motivo de la rehabilitación, ha aparecido el suelo pavimentado y la huella de otra lareira, que en su día es probable fuese idéntica a la citada. Con la nueva obra se ha querido recuperar el recuerdo de esta última, instalando una nueva campana aunque de madera (Fig. 14). Se conserva el vertedero, como el anterior detrás de la puerta ${ }^{54}$. Los cañones exteriores de los tiros de ambas lareiras se disponen paralelamente a ambos lados de la peineta con el escudo capitular. La segunda planta de ambas viviendas, siempre comunicadas por las escaleras compartidas, pienso que se destinarían, en ambos casos, a dormitorios de los habitantes del inmueble.

Una cuestión que queda sin resolver es el porqué se ideó una bóveda para cubrir el vestíbulo principal, a imitación de las de las tiendas. Aunque parece que esta estructura nunca se llegó a terminar de construir y responde a un error 


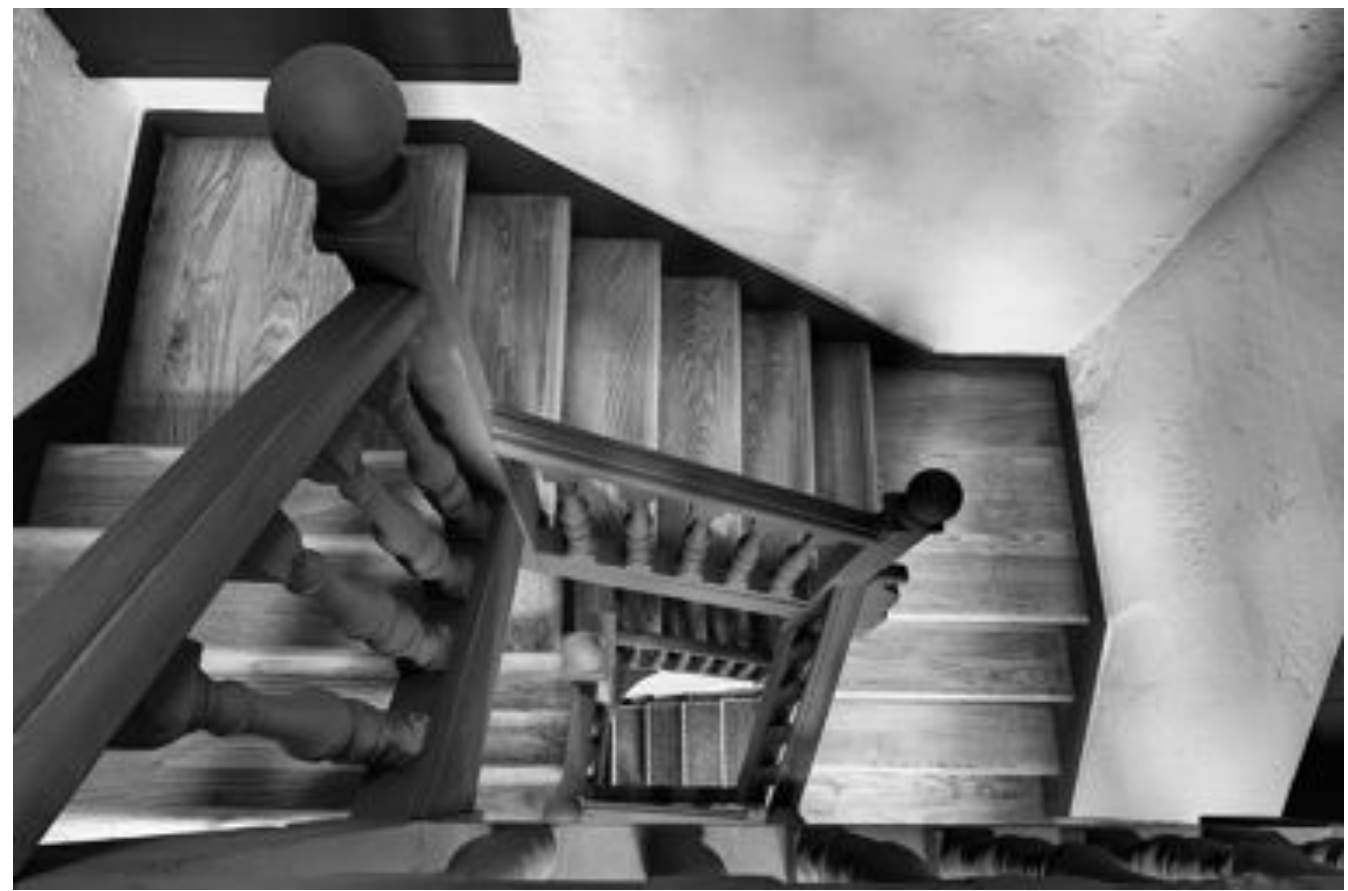

Fig. 12. Escaleras principales de la Casa del Cabildo. Foto Fuco Reyes.

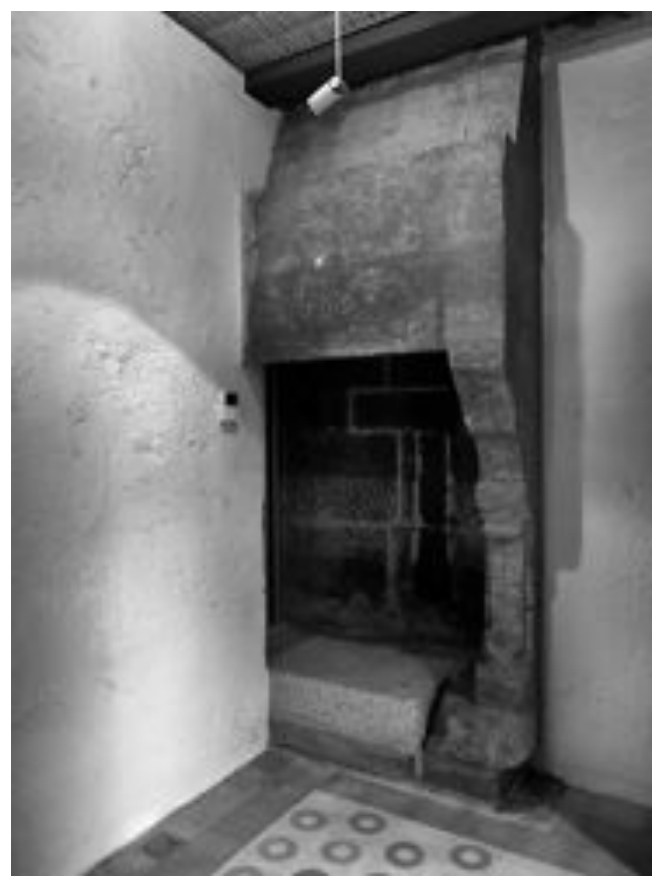

Fig. 13. Lareira de la cocina de la vivienda izquierda de la Casa del Cabildo. Foto Fuco Reyes. o a un cambio de proyecto, su existencia hubiera impedido la habilitación de las escaleras. De ella subsisten los arranques en las pilastras de las esquinas y la rosca de los arcos, destacando el del muro de la medianía.

La existencia de tiendas en el bajo de la casa de Martínez de Mestas hacia Platerías y el Vilar, explica su presencia en el nuevo inmueble (contrastar fig. 7 con la 1 y 2). El aumento de su número, hasta un total de cuatro establecimientos, dos a cada lado del portal de la residencia, con sus correspondientes bancos de piedra donde exponer al público sus productos, se debe a los beneficios que obtendría el Depósito de su arrendamiento a los plateros de la ciudad (Fig. 15). Las cuatro se hayan blindadas con pavimentos de gruesas losas para evitar túneles y robos y abovedadas con piedra para evitar butrones. En la cara interna de los muros norte y sur de las tiendas de la derecha hay huella de la antigua existencia de un tabique separador interior, no muy grueso, que llegaba hasta el capitel, dejando libre la luz del arco. Ello parece indicar que estas tiendas se concibieron para distribuirse de 


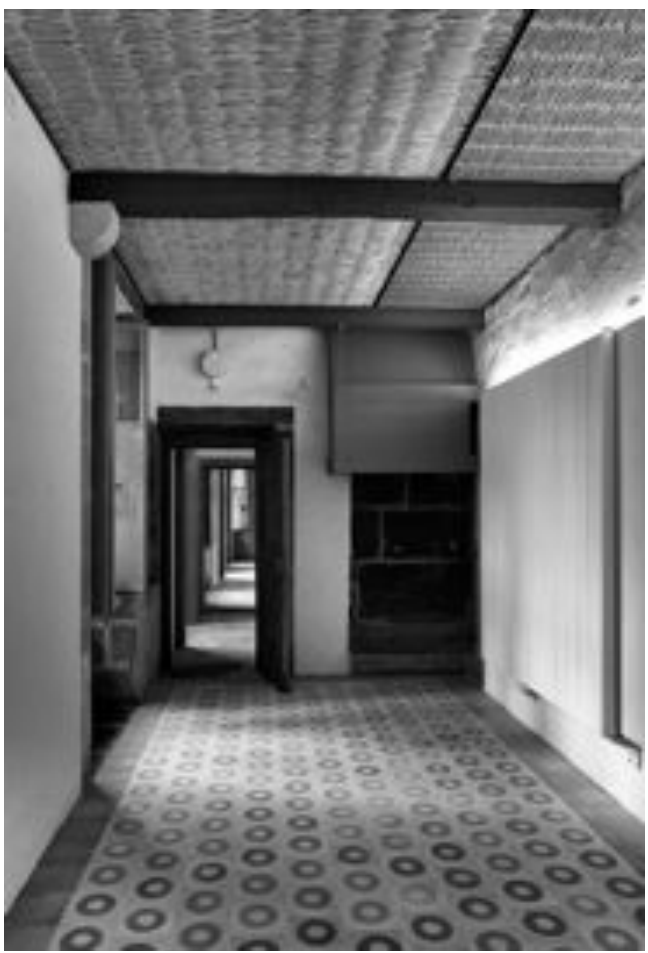

Fig. 14. Aspecto actual de la lareira de la cocina de la vivienda derecha de la Casa del Cabildo. Foto Fuco Reyes.

dos en dos, ocupando cada sector algo más de $20 \mathrm{~m}^{2}$. De ser así, la idea original habría sido distribuir cada parte del bajo a un artesano y su taller de operarios, disponiendo de dos bancos para la venta de los objetos de platería fruto de su trabajo. Recordemos que desde 1418 la Plaza de las Platerías constituía el único espacio urbano donde se permitía a los orfebres y plateros trabajar y vender sus productos. De aquí el nombre actual de la plaza, antiguamente conocida como Praza dos Ourives ${ }^{55}$.

Igualmente el soportal de la casa de Martínez de Mestas en la Rúa do Vilar explica su presencia en la Casa del Cabildo (contrastar fig. 7 con la 1 y 2), respetándose tanto el derecho de paso público de los vecinos, como el del vuelo sobre la calle por parte del nuevo inmueble.

El mantenimiento de la propiedad de la tercera casa por la Fábrica y su no demolición implicó, como hemos visto, que ocupase el bajo y la primera planta del séptimo tramo del nuevo

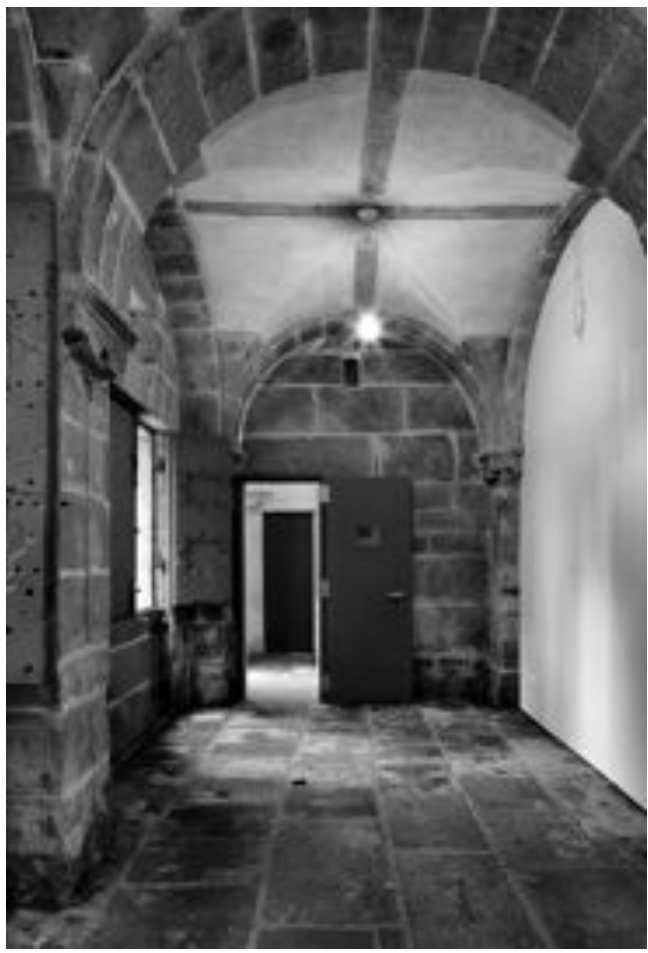

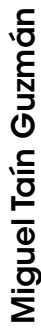

Fig. 15. Vista interior de las tiendas de la derecha. Foto Fuco Reyes.

edificio barroco, extendiéndose el resto de su planta hacia el solar de la Raíña (Figs. 1-9). No abarca la segunda planta de la Casa del Cabildo por ser una nueva altura ganada ahora, aunque, como ya dije, el tiro de sus antiguas chimeneas la atraviesan, perdiéndose bastante espacio útil y generando una pequeña estancia que en tiempos modernos fue transformada en cocina ${ }^{56}$. La Fábrica obligó al mantenimiento del muro medianero original transversal, aquel que en su día separaba esta casa de la de la familia Otero y hoy la separa del interior del monumento. También se instó a respetar las alturas originales de las distintas plantas del viejo edificio, completamente diferentes a las de la Casa del Cabildo: el nivel del suelo de la segunda planta de la Raíña se halla unos 80 centímetros más alto que el de la primera planta del nuevo inmueble. En cambio, en la planta baja la cota cambia completamente, presentando el pavimento de la Casa del Cabildo 26 centímetros más de altura que el del zaguán de la casa vecina ${ }^{57}$. 
Como ya se ha señalado, la Casa del Cabildo mantiene la antigua pared medianera del solar con el caserío trasero, dispuesto al sur, que ya utilizaban las anteriores casas de Martínez de Mesta y de la familia Otero (Fig. 7) y que figura representado en el plano de la ciudad de hacia 1754 (Fig. 5). La primera vivienda compartía dicho medianil con la casa de Juan Hernández, descrito por Fernández Sarela en su informe de septiembre de 1754 como "con grande desplomo y mui ynclinada sobre el centro de esta casa". Ello obligó probablemente a su reparación, aprovechándose la ocasión para engordar parte del muro y disponer en su macizo una escalera secreta de servicio que todavía comunica las tiendas de la izquierda con la primera planta de la vivienda dispuesta encima ${ }^{58}$ (Fig. 16).

La medida de la medianera sur desde la cota de entrada de la puerta principal hasta la parte más alta de la cubierta, pegada al medianil, es de 13,20 metros, lo cual no difiere excesivamen-

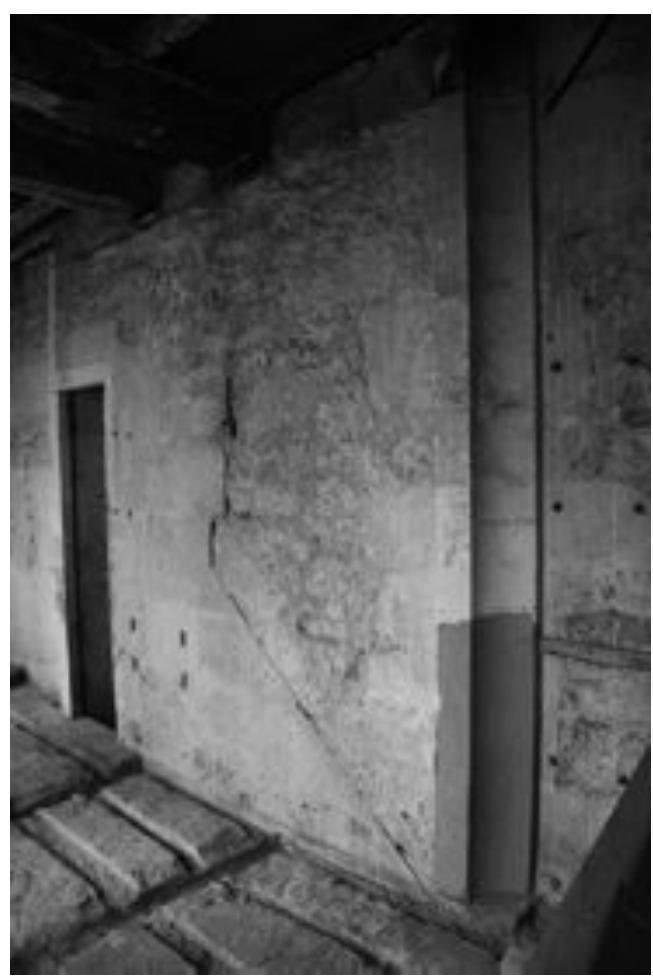

Fig. 16. Escalera "secreta" o de servicio que conduce de las tiendas del bajo a la primera planta de la vivienda de la izquierda de la Casa del Cabildo. te de la altura original de la casa de Martínez de Mesta, calculada, como ya hemos visto, en alrededor de 10,7 metros, pero sí dista y mucho de la altura que debía tener la casa de los Otero. Como sabemos, esta última compartía la medianía con la casa de los Flores, la cual le sobrepasaba ampliamente en altura. Se mantiene, por fin, la pared medianera con la casa de la Fábrica, salvo en la segunda planta, de nueva construcción. Todas estas desigualdades de alturas y de estructuras explican la razón de la construcción de esta fachada telón, que esconde todo ello definitivamente de la vista de los viandantes en una de las plazas más hermosas de Santiago ${ }^{59}$ (contrastar figs. 1 y 7).

En todas las medianías se observa la reutilización de materiales pétreos de anteriores construcciones, hecho habitual en la arquitectura doméstica gallega ${ }^{60}$. Estos bien pueden pertenecer a las construcciones demolidas por Fernández Sarela, aunque no hay que descartar otras posibilidades.

\section{INQUILINOS Y USOS DE LA CASA DEL CABILDO}

También el estudio de la intrahistoria de la Casa del Cabildo ofrece claves para comprender su particular configuración. Terminada de construir, el primero en arrendarla enteramente y con sus tiendas, a su propietario, el Depósito de Música de la Catedral, es Juan Castañín, pintor catedralicio, por la cantidad anual de 1.550 reales, que la ocupa entre 1759 y $1766^{61}$. A él le sigue el platero Antonio de Sousa por 1.950 reales entre 1767 y 1769, por lo que es de suponer que actuaría de manera similar a Castañín ${ }^{62}$. Éste es sustituido en 1770 por el batidor de oro Manuel Vázquez Álvarez, que paga por el edificio 1.600 reales $^{63}$, a su vez reemplazado entre 1789 y 1819 primero por el platero Fernando Torreira y luego por Luis Torreira, posiblemente su hijo, que pagan idéntica cantidad por el arriendo64. Tras él un tal Pablo Oubiña se instala en la casa, donde residirá al menos entre 1819 y 1844, pagando cada año siempre 1.600 reales $^{65}$.

Ya hemos explicado la división interna del inmueble, con dos viviendas de disposición vertical, imitando las dos preexistentes, cada una con su cocina en la primera planta y distribuidas 
en torno a una escalera central. Contradictoriamente, en la documentación vemos como todo el edificio, incluidas las tiendas, han sido siempre arrendadas al Depósito por una única persona, lo que impide saber si el inquilino y sus familias ocupaban el conjunto del inmueble o si subarrendaban una de las viviendas e incluso parte de las tiendas. Lo que sí está claro es que en un momento indeterminado la lareira de la vivienda derecha fue suprimida por no haber necesidad de ella, aunque ésta fue usada durante muchos años dada la gran cantidad de hollín encontrado en el tiro con motivo de la rehabilitación.

Los primeros inquilinos de la Casa son artesanos de cierto poder adquisitivo, interesados en contar con tienda en la plaza, la mayoría plateros puesto que, como ya hemos visto, desde 1418 el perímetro de Platerías era el único lugar en la ciudad donde se permitía dicha actividad. Esta vinculación de las tiendas con los habitantes del inmueble explica que desde las de la izquierda parta una escalera de servicio que las comunica con la primera planta. También que en fecha posterior, indeterminada, se abrieran sendas puertas desde las tiendas de la derecha y de la izquierda al zaguán del inmueble ${ }^{66}$.

La historia del monumento dio un giro radical con motivo de la pérdida de la propiedad por el Depósito a causa de la desamortización de los bienes de la Iglesia de Pascual Madoz del 1 de mayo de $1855^{67}$. Según cuentan los vecinos, a raíz de este suceso lo adquirió la familia González-Moro Cervigón ${ }^{68}$, cuyos descendientes detentaron la propiedad hasta su expropiación en 2008. En esta última fecha el inmueble contaba con siete copropietarios, siendo uno de ellos el conocido militar Rafael González-Moro Vela.

Tal familia lo ha tenido alquilado durante muchos años, aunque, curiosamente, arrendando el inmueble por plantas, lo que explica la citada supresión de la lareira del apartamento derecho de la primera planta, la habilitación de una nueva cocina en la pequeña estancia del extremo oeste del segundo piso y la construcción de un baño en cada planta, el de la segunda en el tiro de las escaleras (Figs. 3-4). Una placa dispuesta en el chaflán de la esquina de la Rúa do Vilar deja constancia de como en ella residió el pintor de origen albaceteño Mariano Tito
Vázquez (1870-1952), que impartía clases en la Escuela de Artes y Oficios y en la Real Sociedad de Amigos del País ${ }^{69}$ (Fig. 17). Según Ana Cambeiro López, pariente del pintor, se instaló en la segunda planta de la casa a principios del siglo XX con su mujer y cuñada, destinando el apartamento de la izquierda a estudio y el derecho a vivienda de la familia ${ }^{70}$. Afortunadamente, nos ha llegado un óleo donde se representa el primero, titulado significativamente Recanto do estudio, que nos sirve para conocer la decoración -muebles, cuadros y platos- de la sala de trabajo del artista después de $1939^{71}$ (Fig. 18). La idea que transmite el cuadro es el de un ambiente íntimo donde reina la comodidad, la luz, el confort y el bienestar ${ }^{72}$. En él se habrían formado artistas compostelanos como González Blanco, Villafínez, Garabal y Concha Vázquez, entre otros muchos ${ }^{73}$.

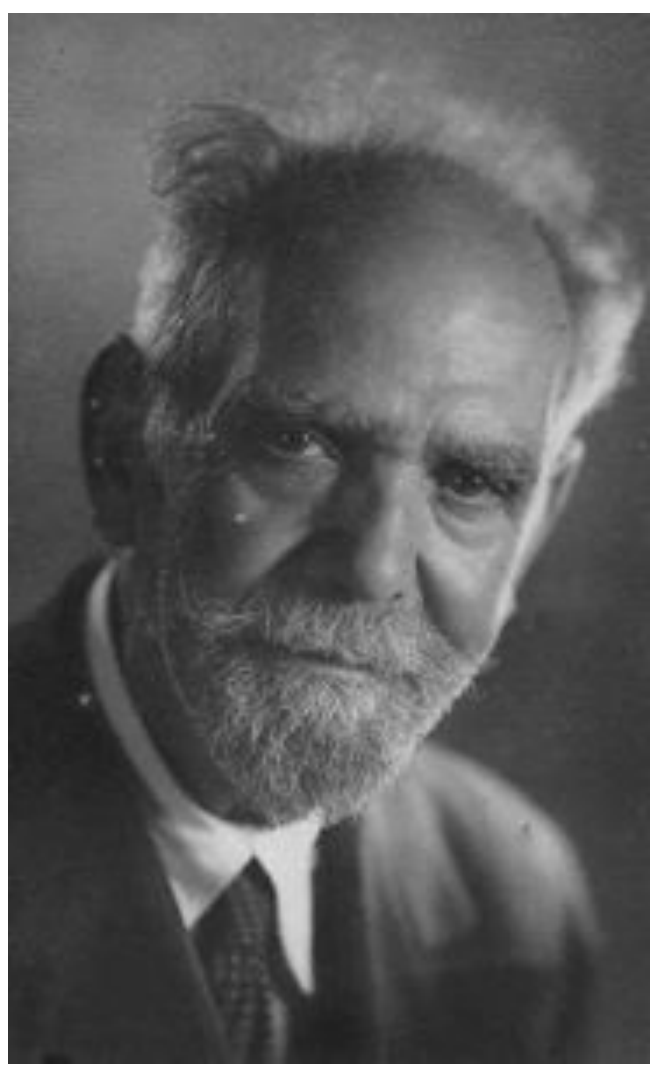

Fig. 17. Retrato del pintor Mariano Tito Vázquez. Foto cedida por la familia. 


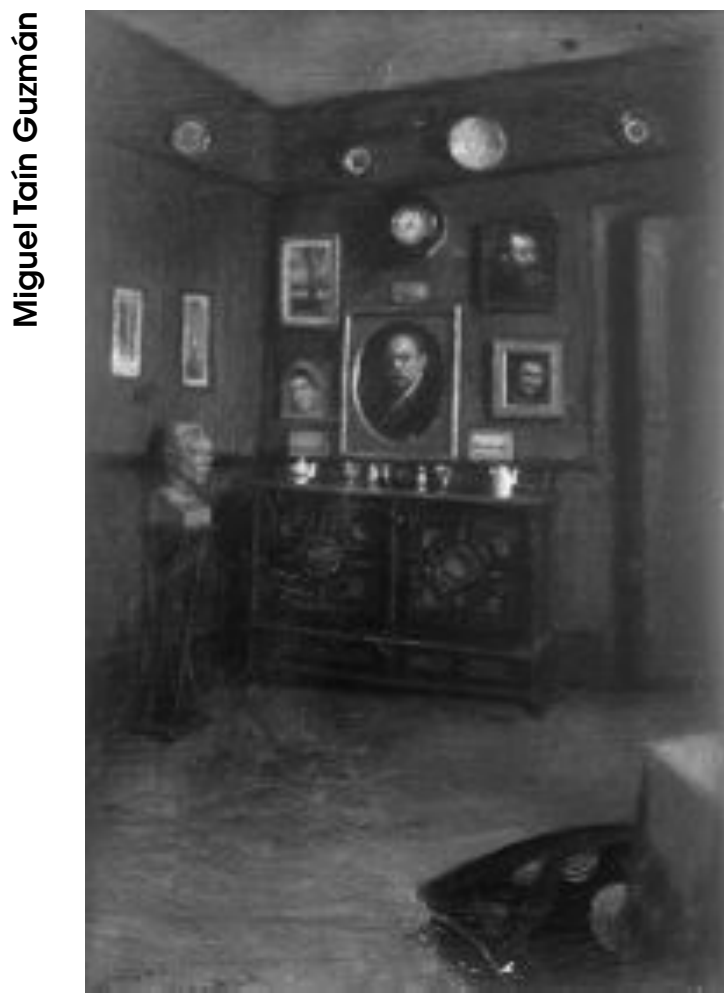

Fig. 18. Mariano Tito Vázquez: Recanto do estudio en la Casa del Cabildo (posterior a 1939). Foto Julio Gil.

Tras su muerte se quedan con la vivienda dos de sus sobrinos. Me refiero a la maestra Isaura López Vázquez, que daba clases en una escuela que había formado en el apartamento izquierdo de dicha planta, con el nombre "Colegio Particular Martín de Herrera"74, y a su hermano Juan Antonio López Vázquez, el cual regentaba una pequeña frutería en el menguado espacio del portal, utilizando los peldaños de la escalera para exponer el género. Ambos acogieron en la casa a los jóvenes de la familia que vinieron a estudiar a la universidad, recordándose todavía hoy con nostalgia las reuniones en los balcones para ver las procesiones ${ }^{75}$ o como subían por unas escalerillas del desván a la terraza de la baranda de los bustos de la cubierta para ver los fuegos del Apóstol, tomar el sol y tender la ropa. La familia deja la casa a finales de los ochenta, quedando desde entonces el inmueble deshabitado y sin ninguna función ${ }^{76}$.
Cuentan los vecinos que en los años cuarenta y cincuenta ocupó la primera planta la familia Hermo, siendo el padre brigada del cuerpo de intendencia, de la que no he localizado más datos ${ }^{77}$.

En cuanto a las cuatro tiendas, desde 1906 las tiene arrendadas la familia Otero, maestros plateros compostelanos muy conocidos en la ciudad, que todavía ocupan las dos tiendas de la izquierda con una joyería de nombre "Joyería Augusto Otero". El primer arrendador fue Bernardino Otero, platero originario de la zona de Carballiño, citado en un documento de $1912^{78}$, que destina las de la izquierda al actual negocio de venta de productos de platería y las de la derecha a talleres para su manufactura. Por estos últimos pasaron muchos aprendices que luego abrieron sus propios puestos en la ciudad. El nombre del fundador todavía se recuerda por ser uno de los autores de la urna con los restos del Apóstol de la catedral. Hacia los años veinte se hace cargo del negocio su hijo Augusto Otero y éste a su vez se lo traspasa al suyo, también de nombre Augusto Otero, en los años cincuenta. Los hijos de este último, Chelo, Augusto y Fernando constituyen los actuales inquilinos ${ }^{79}$. Dado su carácter histórico y pese a la enajenación del inmueble por el Consorcio, el alquiler de la tienda ha sido respetado, manteniéndose su actividad en la actualidad. A él le siguen correspondiendo también las tiendas de la derecha, cuyo uso ha cedido provisionalmente para integrar el circuito museable del edificio rehabilitado.

La Casa del Cabildo figura incluida en el Plan Especial de la Ciudad Histórica con nivel uno, la máxima protección ${ }^{80}$. Ello explica que en marzo de 2007 la junta de gobierno municipal decidiese adquirirlo para instalar en él un centro de interpretación de la ciudad vinculado al nuevo Museo del Banco de España ${ }^{81}$, rechazando la propuesta de la familia propietaria de restaurarlo para abrir en él una exposición de trajes de los siglos XIX y XX82. Como consecuencia, el inmueble fue expropiado por el Consorcio en el 2008, tras ser tasado por una comisión pericial de expertos, encabezada por Antonio Bonet Correa, en 2.289.290 euros ${ }^{83}$. El Ministerio de Fomento y el Ayuntamiento firmaron un convenio el 26 de octubre de 2010 para la financiación de las 
obras de rehabilitación, a la que se destinaron 924.038,06 euros ${ }^{84}$, intervención recientemente terminada y abierta al público.

\section{INQUILINOS Y USOS DE LA CASA DE LA RAÍÑA}

Apenas he localizado datos sobre los inquilinos de la vivienda de la Fábrica, aunque es probable que pertenecieran al colectivo asalariado catedralicio: así, por ejemplo, en 1731 la casa estaba habitada por el presbítero catedralicio Juan Míguez ${ }^{85}$ y, mientras se construía la Casa del Cabildo, por el luminario catedralicio Manuel Faxín, que arrendó el bajo como calera de la nueva obra. ${ }^{86}$

Como para el caso anterior, también el cabildo perdió la propiedad con la desamortización de 1855. Así consta que en 1904 su dueño es el armero José Areosa Hermida en su calidad de tutor de los hijos del finado José Areosa Soto ${ }^{87}$, siendo muy probable que los restos de armas localizadas durante las excavaciones arqueológicas de hace unos meses estén relacionadas con él. Su último propietario ha sido la familia De la Riva que también la tenía alquilada por plantas, lo que explica la existencia de las dos cocinas, viviendo en el primer piso las conocidas hermanas Isabel y Maruja Ayude, esta última casada con Vicente, últimos habitantes del inmueble; y en el segundo la familia Anca. El bajo fue primero una carnicería, regentada por un tal Jesús Rúa desde 1949. Sus parientes, los hermanos Javier y Suso, abrieron en este lugar en 1972 un conocido bar de nombre "Platerías", que se mantuvo en funcionamiento hasta la expropiación ${ }^{88}$. Como el caso anterior, esta casa también fue adquirida por el Consorcio para acometer las obras recién terminadas.

\section{NOTAS}

${ }^{1}$ Con motivo del contrato firmado entre el Consorcio y la Universidad de Santiago el 28 de enero de 2011 (referencia 2011/CI211) para la elaboración de un estudio histórico destinado a la rehabilitación de la Casa del Cabildo, por iniciativa de José Manuel Villanueva Prieto, gerente del Consorcio, y Ángel Panero Pardo, Director de la Oficina Técnica, surge el presente artículo, donde se recogen mis conclusiones. Aparte de las personas mencionadas, otras muchas han contribuido a la realización de esta investigación, dejando constancia aquí de mi agradecimiento a todas ellas, particularmente a Juan Conde Roa, José María Díaz Fernández, Julio Gil, Domingo González Lopo, José Manuel López Vázquez, Cristina Mato Fresan, Marco di Mauro, Juan María Montijano García, Juan Monterroso Montero, Alfredo Morales Martínez, Lourdes Pérez Castro, Patricia Pérez Dorado, Juan Pedro Pérez Pérez, Ofelia Rey Castelao, Fuco Reyes, Alfredo Solla y Jorge Vázquez Couto.

2 Para valorar el palacio compostelano en el contexto de la arquitectura doméstica española del siglo XVIII véase B. Blasco Esquivias (dir.), La casa. Evolu- ción del espacio doméstico en España, vol. I, Edad Moderna, Madrid, 2006.

${ }^{3}$ Cfr. E. Orozco Díaz, El teatro y la teatralidad del Barroco, Barcelona, 1969, 149-156.

${ }_{4}$ Al respecto véase G. Ramallo Asensio, "El rostro barroco de las catedrales españolas", Cuadernos Dieciochistas, 2000, 313-347.

5 Sobre el fenómeno véase $M$. Fagiolo, "Le facciate effimere", en M. Fagiolo (dir.), La Festa a Roma. Dal Rinascimento al 1870. Atlante, vol. II, Torino-Roma, 1997, 198-206, particularmente la 203-206.

6 Cfr. Renato De Fusco, L'architettura del Cinquecento, Torino, 1981, 185-188.

7 Cfr. G. Carpaneto, I Palazzi di Roma, Roma, 1998 ( $1^{\text {a }}$ ed. 1991), 135136.

${ }^{8} \mathrm{Cfr}$. M ${ }^{\mathrm{a}}$. del C. Folgar de la Calle, Arquitectura gallega del siglo XVIII. Los Sarela, Santiago, 1985, 111.

${ }^{9}$ Cfr. A. A. Rosende Valdés, Una historia urbana: Compostela 15951780, Santiago, 2004, 250.

10 Para éstos y otros ejemplos véanse los volúmenes publicados desde 2002 en la colección Atlante del Barocco in Italia dirigida por Marcello
Fagiolo y patrocinada por el Comitato Nazionale per Roma Barocca, el Centro di Studi sulla Cultura e I'Immagini di Roma y la Università degli Studi di Roma La Sapienza.

${ }^{11}$ Cfr. P. Portoghesi, Roma barocca, Roma-Bari, 1992, 8-9

${ }^{12}$ Cfr. J. Escobar, La Plaza Mayor y los orígenes del Madrid Barroco, Madrid, 2007.

${ }^{13}$ Cfr. A. Rodríguez Gutiérrez de Ceballos, La Plaza Mayor de Salamanca, Salamanca, 1991 (2 ${ }^{a}$ ed. corr.).

${ }^{14}$ Cfr. V. Tovar Martín, "Juan Gómez de Mora, arquitecto y trazador del rey y maestro mayor de obras de la villa de Madrid", en V. Tovar Martín (comisaria), Juan Gómez de Mora (1586-1648), arquitecto y trazador del rey y maestro mayor de obras de la viIla de Madrid, Madrid, 1986, 40-52; y R. Diez del Corral, "El Alcázar de Juan Gómez de Mora", en F. Checa (dir.), El Real Alcázar de Madrid. Dos siglos de arquitectura y coleccionismo en la Corte de los Reyes de España, Madrid, 1994, 152-157

${ }^{15}$ Cfr. V. Tovar Martín, "Arquitectura", en El Arte del Barroco. Arquitectura y escultura, Taurus, Madrid, 1990, 110-141. 
${ }^{16}$ Se concibe a modo de pantalla cinco metros por delante del edificio medieval, alterando considerablemente la iluminación original de las estancias interiores; cfr. A. Bonet Correa, La arquitectura en Galicia durante el siglo

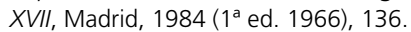

17 Cfr. M. Taín Guzmán, Domingo de Andrade, Maestro de Obras de la Catedral de Santiago (1639-1712), Sada-A Coruña, 1998, vol. I, 279-291.

${ }_{18}$ Cfr. O. Schubert, Historia del Barroco en España, Madrid, 1924, 274-276.

${ }^{19} \mathrm{Cfr}$. G. Kubler, Arquitectura de los siglos XVII y XVIII, en Ars Hispaniae. Historia Universal del Arte Hispánico, vol. XIV, Madrid, 1957, 355.

${ }^{20}$ Cfr. E. Valdivieso González, "La arquitectura española del siglo XVIII", Arte Español del Siglo XVIII, Summa Artis, Historia General del Arte, vol. XXVII, Madrid, 1984, 643.

${ }^{21}$ De ello ya advirtieron J.J. Martín González, "Perspectivas barrocas de Santiago de Compostela", Goya, 1964, 31 y A. Bonet Correa, "La estructura urbana de Santiago de Compostela", Proyecto y ciudad histórica, Primer Seminario Internacional de Arquitectura en Compostela, COAG, Santiago, 1976, 33.

${ }^{22}$ Cfr. V. Tovar Martín, "Arquitectura", op. cit., 182.

${ }^{23} \mathrm{Al}$ respecto merece destacarse que todavía se conservan los cierres originales de las dos tiendas de la derecha, la puerta principal del edificio y las cuatro puertas interiores de las dos plantas del interior, todo ello piezas maestras de la carpintería compostelana del siglo XVIII.

24 Institución dependiente del cabildo catedralicio que gestionaba y mantenía la Capilla de Música con las rentas de la tercera parte del Voto de Granada y algunas propiedades de la ciudad.

${ }^{25}$ Así se decide en el cabildo del 25 de junio de 1754; A.C.S. (Archivo de la Catedral de Santiago), Libro 55 de Actas Capitulares, leg. 524, fol.238v. Sobre la relevancia del canónigo véanse $\mathrm{M}^{\mathrm{a}}$. del C. Folgar de la Calle, "Promotores del Barroco Gallego: D. Diego Juan de Ulloa", Actas del I Congreso Internacional do Barroco, Porto, 1991, vol. I, 371-396; M. Taín Guzmán, "La biblioteca del canónigo maestrescuela Diego Juan de Ulloa, impulsor del Ba- rroco compostelano", Semata, Cultura, Poder y Mecenazgo, 1999, 321-357.

${ }^{26}$ Los gastos incluyen la construcción de una nueva fuente en Platerías (la actual es posterior) y el arreglo de la pavimentación de la plaza; A.C.S., Cuentas de las rentas del Depósito, libro 2, leg. 620, fols. 95v.-96r. y 119 r.

27 Un recibo deja clara su autoría: "Más a Sarela, por la planta para la obra, di en 5 [de] marzo [de] 1756 [la cantidad de] 300 reales"; A.C.S., Tenencias, caja 85/1, Casa que hace frente a la Plaza y Puerta Meridional de esta Santa Iglesia que se fabricó por el Depósito para adorno y ensanche de la Plazuela, fol. 136v. Para una idea general de la relevancia de su figura véase $\mathrm{M}^{a}$. del $\mathrm{C}$. Folgar de la Calle, LoS Sarela, op. cit.; id., "Os Sarela", en C. del Pulgar Sabín (ed.), Artes Gallegos. Arquitectos. Séculos XVII e XVIII, Vigo, 2004, 382-413.

${ }^{28} \mathrm{Al}$ inmueble ya había dedicado su atención con anterioridad, con gran brillantez, Ma . del Folgar de la Calle, Los Sarela, op. cit., 102-115. Recientemente también A. A. Rosende Valdés, op. cit., 249-253.

${ }^{29}$ Ambas instituciones las habían arrendado a un tal Fernando Figueroa Campelo y Castro, quien a su vez las había subforado a los citados Martínez de Mestas y Ventura Otero. Toda la documentación referida a la adquisición del solar y los gastos habidos en la construcción del nuevo inmueble se encuentra en tres legajos del A.C.S.: uno, con la referencia Tenencias, caja 85/1, Casa que hace frente a la Plaza y Puerta Meridional de esta Santa Iglesia que se fabricó por el Depósito para adorno y ensanche de la Plazuela; un segundo, dedicado exclusivamente a las cuentas de la nueva obra que comienzan la semana del 22 de febrero de 1755 , en Casa de la esquina de la Fuente de la Platería, leg. 422, Dacta que da Don Román Mourelos, cappellán de choro, por semanas de la obra de la esquina de la Fuente de la Platería al señor Don Diego Juan de Ulloa, canónigo dignidad, maestrescuela y administrador de la obra de el Depósito de ella, sin foliar; y por fin, el tercero, dedicado igualmente a los gastos de las obras en los últimos años en leg. 422, Casa de la Platería, 1758 y 1759, sin foliar.

${ }^{30}$ Institución capitular que mantenía el culto y el edificio de la catedral con rentas sobre todo patrimoniales y crediticias.

${ }^{31}$ Fecho el plano como de meses antes a 1754 porque en él no figura la Capilla de las Angustias, hoy iglesia de San Fructuoso, comenzada a construirse en dicho año de 1754 por Lucas Ferro Caaveiro. Plano publicado en $\mathrm{M}^{\mathrm{a}}$. L. Sobrino y P. de Llano (coords.), Cartografía básica da cidade de Santiago de Compostela, Consello da Cultura Galega, Santiago, 1990.

32 A.C.S., Tenencias, caja 85/1, Casa que hace frente a la Plaza..., fols. 53r.-60r.

${ }^{33}$ Se refiere al cruce de calles entre la Rúa do Vilar y la Rúa de Xelmírez.

${ }^{34}$ A.C.S., Libro 55 de Actas Capitulares, leg. 524, fol. 238v.; un extracto de este documento figura publicado en B. J. Quijada Morandeira, Las obras en la Catedral de Santiago desde 1751 a 1800. Aportación documental, A Coruña 1997, 113.

35 A.C.S., Tenencias, caja 85/1, Casa que hace frente a la Plaza..., Protocolo sobre la venta del útil de las dos primeras casas del 19 de enero, fol. 4 r.

${ }^{36}$ Se la cita en el informe de la nota siguiente.

37 A.C.S., Tenencias, caja 85/1, Casa que hace frente a la Plaza..., fols. 38r.-40r.

${ }^{38}$ El bajo y el entresuelo medían alrededor de 5,3 metros (25,5 cuartas y 1 dedo), sólo el entresuelo 2,5 metros (12 cuartas menos 1 sesma), el primer piso alrededor de 2,9 metros (14 cuartas y 3 dedos) y el segundo hasta el tejado alrededor de 2,4 metros (11,5 cuartas). Como se observa, en la documentación se utiliza como sistema de medidas la vara castellana (835 milímetros y 9 décimas), la cuarta (21 centímetros) y el dedo (18 milímetros).

${ }^{39}$ Según el documento, cuando se redacta el informe la casa pertenece al citado Fernando Figueroa y está habitada por un tal Domingo Soto (A.C.S., Tenencias, caja 85/1, Casa que hace frente a la Plaza..., fols. 19r.-20v.).

40 A.C.S., Tenencias, caja 85/1, Casa que hace frente a la Plaza..., fols. 40v. $-42 r$.

${ }^{41}$ Salvo que se indique lo contrario, todas las medidas han sido facilitadas por la Oficina Técnica del Consorcio.

42 Se la cita en el informe de Fernando de Casas. 
${ }^{43}$ Medidas extraídas del informe de Sarela.

${ }^{44}$ La misma fue descubierta al retirarse los revocos de la pared durante la reciente rehabilitación.

${ }^{45}$ Contando de izquierda a derecha.

${ }^{46}$ Antes de la reforma de 2011 presentaba $120,17 \mathrm{~m}^{2}$ de superficie construida.

${ }^{47}$ De entonces data el recrecido de la vertiente sur del tejado y, acaso también, la solicitud de una licencia al Ayuntamiento en 1904 para instalar un nuevo desagüe en el nuevo fregadero (A.H.U.S., Sección Ayuntamiento de Santiago, Licencias para obras, 1904, libro 583, fols. 1r.-7v.).

${ }^{48}$ Ello contrasta con la plasticidad, volumen y movilidad del cuerpo alto del edificio donde ya no hay estas limitaciones.

49 A.C.S., Tenencias, caja 85/1, Casa que hace frente a la Plaza..., Venta del útil de dos casas inclusas en la fachada vaxo de la fuente de la Platería (19 de enero de 1768), fol. 4 r.

${ }^{50}$ Desde la pared medianera sur a la contrafachada interna del palacio (he medido en la primera planta).

${ }^{51}$ Desde la pared medianera sur a la contrafachada interna del palacio.

52 Cfr. B. Blasco Esquivias, "Los espacios de la necesidad: alimentación, higiene y descanso nocturno", en B. Blasco Esquivias (dir.), op. cit., 38-43.

53 Tales elementos todavía son típicos en cualquier casa popular del país; cfr. P. de Llano, Arquitectura popular en Galicia, vol. I, Vigo, 1981, 58-62; M. Caamaño Suárez, Las Construcciones de la Arquitectura Popular. Patrimonio etnográfico de Galicia, Santiago, 2003, 129-134.

${ }^{54}$ Sospecho que los conductos de desagüe de ambos vertederos se hallan en la fachada principal del edificio, posiblemente en el interior de algunas de las pilastras que lo recorren verticalmente.

${ }^{55}$ Véase A. A. López Ferreiro, Historia de la Santa A.M. Iglesia de Santiago de Compostela, Santiago, 1905, t.VII, 75-79.

${ }^{56}$ Esta cocina ha de ser posterior y consecuencia de la supresión de la lareira de la primera planta.

${ }^{57}$ A nivel de la Raíña aún es mucho más bajo, alrededor de 1,07 metros, y se salva con unas escaleras.
${ }^{58}$ Con motivo de la rehabilitación se ha procedido a retirar los escombros que tapiaban dicha escalera, descubriéndose el acceso a la tienda inferior. Sospecho que dicho tapiaje es fruto de una intervención no muy lejana, cuando los inquilinos de las tiendas inferiores y los habitantes de la vivienda no eran los mismos, queriendo evitar con ello la posibilidad de robos por dicho acceso.

${ }^{59}$ Para una visión general sobre las funciones de esta plaza y su importancia en el entramado urbano véase A.A. Rosende Valdés, op. cit., 233-260.

${ }^{60} \mathrm{Cfr}$. Ma ${ }^{\mathrm{a}}$. A. Fernández Álvarez, Arte y sociedad en Compostela 16601710, Sada-A Coruña, 1996, 39.

${ }^{61}$ Un documento dice lo siguiente: "Más 1.550 reales que paga Juan Castagnín por el arriendo de la casa nueva frente de la fuente de la Platería que fabricó de nuevo el Depósito. $1^{\text {a }}$ paga y año cumplido" (A.C.S., Cuentas de las rentas del Depósito, Libro 2, leg.620, fols.131v.-132r. (año 1759), 133v. (año 1760), 159v.-160r. (año 1761), 163v. (año 1762), 166v. (año 1763), 194v. (año 1764), 196v. (año 1765) y $221 \mathrm{v}$. (año 1766).

${ }^{62}$ A.C.S., Cuentas de las rentas del Depósito, Libro 2, leg.620, fols. 225r. (año 1767), 227v. (año 1768) y 259r. (año 1769).

${ }^{63}$ A.C.S., Cuentas de las rentas del Depósito, Libro 2, leg.620, fols. $261 \mathrm{r}$. (año 1770), 263r. (año 1771), 284v. (año 1772), 287v. (año 1773), 290v. (año 1774), 293v. (año 1775), 296v. (año 1776), 299r. (año 1777) y 336v. (años 1775-1778), y Libro 3, leg. 621, fols. 4r. (año 1778), 7r. (año 1779), 9v. (año 1780), 24r. (pago de deuda), 35v. (año 1781), 37v. (año 1782), 40r. (año 1783), 42v. (año 1784), 44v. (año 1785), 47r. (año 1786), 49v. (año 1787) y 52 r. (año 1788).

${ }^{64}$ A.C.S., Cuentas de las rentas del Depósito, Libro 3, leg.621, fols. 96r. (año 1789), 99r. (año 1790), 102r. (año 1791), 105r. (año 1792), 139r. (año 1793), 142r. (año 1794), 143v. (año 1795), 145r. (año 1796), 173v. (año 1797), 175v. (año 1798), 194r. (pago de deuda), 203r. (año 1799), 205r. (año 1800), 234v. (año 1801), 237r. (año 1802), 239r. (año 1803), 275v. (año 1804), 277v. (año 1805), 293r. (pago de deuda), 302v. (año 1806), 314v. (pago de deuda), 325r. (año 1807), 345r. (año
1808), 347r. (año 1809), 361v. (pago de deuda) y 369v. (año 1810 y hasta el día de San Juan de 1811); A.C.S., Libros del Depósito, leg. 616, Cobrador de las rentas del Depósito desde 1810, fol.29r.v. (años desde 1810 hasta la navidad de 1819) y Gastos de 1811-14, fols. 6r. (año 1811), 8r. (año 1812), 9v (año 1813) y 11v. (año 1814). He encontrado uno de los contratos de arrendamiento firmados por Torreira por siete años, con fecha del 3 de junio de 1793. Su lectura es interesante por las condiciones que enumera: "cuia casa por el tenor de la presente arrienda... a Don Fernando Torreira, platero, vecino de esta expresada ciudad, su muger, hixos $y$ herederos..., con todas sus entradas $y$ salidas a ellas a anexas y pertenecientes, por tiempo y espacio de siete años. Respecto al presente la esta viviendo y poseiendo en renta, canon y pensión en cada uno de dichos siete años de mil y seiscientos reales [de] vellón, que ha de pagar en dos pagas yguales de por metad por San Juan de junio y Natividad del propio año... Y con la condición y calidad de que ha de traer dicha casa vien reparada de todo lo necesario, sus vidrios sanos y compuestos los que se hallen rotos en las salas, y sus mayneles, sin que por dicha composición pueda pedir ni repetir cosa alguna. Mediante quando entró a vivirlos los tenía todos buenos, nuebos y sanos, sin faltarle alguno... Y tener todo cuidado en traer limpias y aseadas la expresada casa $y$ sus oficinas" (A.C.S., Tenencias, caja 85/1, Casa que hace frente a la Plaza... fols. 2 r.-3r.). Sobre este artífice véase J. Couselo Bouzas, Galicia Artística en el siglo XVIII y primer tercio del XIX, Compostela, 1932, 631

${ }^{65}$ A.C.S., Libros del Depósito, leg. 616, Cobrador de las rentas del Depósito desde 1810, fols. 29v.-30v. (años 1819-1844) y leg. 618, Depósito desde 1821 hasta 1832, sin foliar; Cuentas de los años 1833-1835, sin foliar; Cuentas de los años 1836-1837, sin foliar; Cuentas del Depósito de 1838, sin foliar; Cuentas del Depósito de 1840, sin foliar; Cuentas del depósito de 1841, sin foliar.

66 Según cuenta Ana Cambeiro López, en tiempos de su tío abuelo, el pintor Mariano Tito, inquilino de la segunda planta como luego se verá, la puerta de la derecha fue forzada por unos ladrones, saqueándose el taller de la joyería Otero allí instalado. 
${ }^{67}$ Cfr. A. Iglesias Ortega, F.M. Sandoval Verea y $\mathrm{M}^{\mathrm{a}}$. Seijas Montero, Inventario de Casas y Tenencias, Archivium Sancti lacobi, Instrumentos de descripción, Santiago, 2009, 18. Sobre como afectó esta desamortización a las propiedades inmobiliarias de la iglesia española véase F. Martí Gilabert, La desamortización española, Madrid, 2003, 81-102.

${ }^{68}$ Un documento de 1912 indica que era propiedad de Francisca Carrera Presas, viuda de Cervigón; A.H.U.S. (Archivo Histórico Universitario de Santiago), Sección Ayuntamiento de Santiago, Licencias para Obras, $2^{\circ}$ apéndice, libro 603, fols. 295r.-302r.

${ }^{69}$ Dicha placa se pagó con el dinero de una subasta de cuadros previamente expuestos para ello; Cfr. Exposición Homenaje póstumo a Mariano Tito Vázquez: sus discípulos y artistas de Galicia, Casa de la Parra, Santiago, mayo 1953.

${ }^{70}$ Los mismos acogieron en su casa a numerosos familiares que vinieron a Santiago a estudiar o trabajar, entre ellos sus cuatro sobrinos Sofía, Isaura, Juan Antonio y Amelia.

${ }^{71}$ En el cuadro aparece abierta la puerta que comunica con las escaleras principales de la Casa. En la actualidad el cuadro es propiedad de Ana Cambeiro López. Podemos fecharlo porque en el mismo aparece representado colgado en la pared un autorretrato del artista, datado de 1939, propiedad hoy del Museo de Bellas Artes de A Coruña (inv. 895); información facilitada por Patricia Pérez Dorado.

72 Véanse estos conceptos en W. Rybczynski, La casa. Historia de una idea, Guipúzcoa, 1999 (1ª ed. 1989).

${ }^{73}$ Sobre su biografía y obra véanse J. M. López Vázquez, "Mariano Tito Vázquez", en Artistas Gallegos. Pintores, O rexionalismo I, A Coruña, 1997, 103-140.

${ }^{74}$ Popularmente se la llamaba la "escuela de Platerías".

${ }^{75}$ Esta función de los balcones de la casa como palcos para las fiestas de la ciudad podría explicar la presencia de argollas en la fachada que, más que para colgar tapices y colgaduras con los que engalanar el edificio, sospecho se utilizaron para los toldos que entoldaban Compostela con motivo de algunas fiestas. Al respecto es ilustrativo un dibujo antiguo de las Platerías entoldada con motivo de una procesión; véase reproducción del dibujo en M. Taín Guzmán, La Casa del Deán de Santiago de Compostela, A Coruña, 2004, 168, fig. 229.

76 Información facilitada por Ana Cambeiro López, hija de Sofía, que residió en la casa entre 1952 y finales de los años ochenta.

77 Según parece, dejaron la casa en los años setenta.
78 Se trata de la licencia para ampliar el hueco de la tienda hacia la Rúa do Vilar; A.H.U.S., Sección Ayuntamiento de Santiago, Licencias para Obras, $2^{\circ}$ apéndice, libro 603, 1912, fols. 295r.-302r. milia.

79 Noticias facilitadas por la fa-

$80 \mathrm{http}: / / \mathrm{sip}$. consorciodesantiago. org/SIPWeb/\#p=4\&s=0\&v0=510701

${ }^{81}$ El Correo Gallego, 13 de marzo de 2007. 2007.

${ }^{82}$ El Correo Gallego, 5 de julio de

${ }^{83}$ Cfr. "El Consorcio compra la casa del Cabildo por dos millones", El Correo Gallego, 8-10-2008; E. Ferrer, "La fachada de los dos millones", Sietemagazine, 11 de julio de 2008

${ }^{84} \mathrm{Cfr}$. "Convenio para rehabilitar la Casa del Cabildo, en Platerías", El Correo Gallego, 26 de octubre de 2010.

${ }^{85}$ Así se afirma en el informe de Fernando de Casas.

${ }^{86}$ A.C.S., leg. 422, Casa de la Platería, 1758-1759, sin foliar.

${ }^{87}$ Es él quien solicita permiso al Ayuntamiento para instalar una nueva cañería que recoja las aguas del fregadero; A.H.U.S., Sección Ayuntamiento de Santiago, Licencias para obras, 1904, libro 583, fols. 1r.-7v.

${ }^{88}$ Noticias facilitadas por la familia y los vecinos. 